\title{
Architectural Interventions to Mitigate Occupational Stress Among Office Workers
}

\author{
Hirbod Norouzianpour
}

\begin{abstract}
Stress is one issue that affects the health and well-being of every building occupant. The negative effects of stress are more pronounced in workplaces, where stress can act as a major agent of disease and an impediment to employee productivity and satisfaction. The underlying causes of occupational stress are varied and include job insecurity, extended hours, excessive workload, altercations within the organization, tight deadlines, changes in responsibilities, and lack of autonomy, among others. One of the factors that can contribute to overall occupational stress is the working environment itself-a factor that can be mitigated by design. While occupational stress may arise from a multiplicity of causes, designers have numerous interventions they can employ to decrease it.

The literature on occupational health, well-being, satisfaction, and productivity is broad and multifaceted; however, this paper is limited to exploring stress factors that correlate with the built environment and focuses on employees who are experiencing a high rate of stress in office buildings as the target group. To address these issues, supporting literature was explored to identify environmental interventions that could reduce stress or enhance the stress-coping abilities of workers in offices by improving the environmental quality of the built environment.

This article explores the following questions: How does space cause people to experience mental stress? In what ways can the built environment itself be a generator of stress? What are the main environmental factors in offices that can mitigate the stress levels of employees or help them to recover more easily from work-related stress? To answer these questions, it is necessary to understand the causes and mechanisms of chronic stress, including workrelated stressors, and to identify the factors in the built environment that can be associated with occupational stress. The present paper is based on concurrent analyses of supporting literature in the rather different fields of architecture, public health, psychology, management, and environmental studies. The outcome is an identified set of practical strategies that provide solutions for healthier and more productive workplaces. By concentrating on measures that can reduce employee stress levels, these strategies can be used as a source for evidence-based workplace designs.
\end{abstract}

Keywords: occupational stress, office building, COVID-19, evidence-based design, biophilic design.

\section{Introduction}

Public health is an increasingly multidisciplinary field, one which touches on social, economic, medical, and environmental concerns. Although public health has not traditionally been the core concern of architecture studies, it has more recently been a growing concern as architects are ever more cognizant of the

Stable URL: https://arcc-journal.org/index.php/arccjournal/article/view/1069

DOI 10.17831/enq:arcc.v16i2.1069

Corresponding Author: Hirbod Norouzianpour<hirbod@unm.edu>

Published by the Architectural Research Centers Consortium under the terms of the Attribution-NonCommercial-ShareAlike 4.0 International license 
many ways in which the built environment can have significant effects on its users and their health and well-being (Rider et al. 2018). One of the reasons behind this growing interest is the fact that there has been an extensive shift from the manufacturing sector to the service and knowledge sectors; additionally, workers spend more time than in previous decades in indoor environments (Al Horr et al. 2016). Also, recent years have seen a growing recognition by managers of the importance of the health and wellbeing of workers as critical to the success of organizations and the acknowledgment that the staff is the most valuable resource of any organization. Due to the importance of the satisfaction of employees for productivity and their well-being, providing a healthy work environment is a crucial component for resource optimization. At the same time, however, people are now facing more stress due to the fast pace of urban lifestyles and work demands (Gruebner et al. 2017). In fact, even though cities now provide better healthcare facilities than in the past, they expose more people to environmental and social risk factors that cause stress (Gruebner et al. 2017), which is itself a contributing factor to many diseases. Accordingly, today, public health is becoming, indisputably, a major design concern. Moreover, the COVID-19 pandemic has underscored the fact that our current workplace design paradigms need to be revisited and improved.

Occupational stress is considered the agent and built environment as a vector and risk factor for causing diseases. The negative impacts of stress are not limited to mental health problems; they are also considered a source of many medical problems such as diabetes, high blood pressure and weight issues (Adli 2011). Accordingly, designers now face the challenge of mitigating stress in workplaces. The critical questions that should be answered by architects for healthier workplaces are: 1) what are the main environmental factors in offices that can help employees experience lower stress levels? and 2) what elemental factors can help employees recover from the stress that they, inevitably, may experience even when attention is paid to its causes?

In this paper, I discuss how the built environment affects the workplace and identify design interventions that help reduce employees' stress levels. The target population in this research consists of highly stressed employees - those facing chronic stress in offices daily - in order to develop strategies that will improve their well-being via environmental evidence- based design. The ultimate goal of this research is to present a picture of healthier and happier working environments that help each employee to function more productively and successfully. Thus, reducing stress and elevating personal moods in offices by environmental improvement is an explicit mission of this review. The outcome of this study is a set of practical architectural strategies.

\section{Research method}

For decades, stress has been a topic in many fields including public health, occupational health, neuroscience, psychology, healthcare, social sciences, environmental studies, urban studies, planning, medical sciences, and management. In fact, the study of the relationship between environmental factors and employees' productivity and well-being can be traced back to 1920 (Al Horr et al. 2016). Most research on occupational stress focuses on the general well-being of workers, which can be operationalized by considering factors including productivity, employee satisfaction and mental health.

Supporting literature in the fields enumerated above was used to begin to translate a public health issue into the language of architecture and to frame a discussion of possible design interventions in order to address the issue of stress in the workplace more effectively. Fortunately, public health issues in architecture have been receiving more attention in recent years (Rider et al. 2018), thus providing a variety of resources to work with as a starting point for research in this field. Using the funnel method to direct the literature review was central to drawing a usable conclusion and avoiding generalization.

Accordingly, the present paper aims to identify the relationship between occupational stress and the built environment in the workplace through a multidisciplinary literature review. After a comprehensive bibliographic data search on mental health and built environment (with abstract screening), 209 publications which address occupational stress to some extent were selected for review. Eventually, 78 whose content was germane to the topic of this paper were selected for citation.

Although different databases were used for this research, the primary source was PubMed, the Web of Science, Google Scholar, and Research Gate databases. Keywords and search terms used included "stress and built environment," "stress at workplace," 
"stress, psychological," "occupational stress," "workplace," and "employment." In addition to providing categories for classifying potential intervention strategies for reducing occupational stress, this exploration identified areas that merit further research, experiments and primary studies.

\section{Causes and effects of occupational stress in the work environment}

Occupational risk factors are defined as any chemical, biological, physical, or other factors that can harm a person in the workplace and that can be modified (Barientos et al. 2004, 21). Congruent with this definition, stress is an occupational risk factor since it can affect people's neurophysiological and other physical responses (Figueroa-Fankhanel 2014) and, in many cases, can be mitigated. Chronic stressors are associated with the destruction of normal cellular and humoral processes (Segerstrom and Miller 2004) which can lead to heart disease, cancers, musculoskeletal injuries, type 2 diabetes along with related discomfort, disability, and shortened lifespan (Quick and Henderson 2016; Kivimäki and Kawachi 2015; Epel et al. 2004).

In general, stress - an internal state - is a real or perceived agitation that puts the physiological or psychological wellbeing of an organism at risk. In response, the body tries to return to its normal, unagitated state by utilizing a variety of behavioral or physiological tools and reactions (National Research Council (US) Committee on Recognition and Alleviation of Distress in Laboratory Animals 2008). Distress, on the other hand, is a state of physical or psychological pain and suffering that is caused by stress (Figueroa-Fankhanel 2014), and can be classified as medical, psychological and/or behavioral (Quick and Henderson 2016). In a distressed state, the organism's coping and adaptation tools cannot restore physiological and/or psychological situations to levels that are optimum for survival, or to homeostasis (National Research Council (US) Committee on Recognition and Alleviation of Distress in Laboratory Animals 2008).

At the individual level, medical distresses such as heart disease, cancers, and musculoskeletal injuries, along with related discomfort and disability are wellstudied (Quick and Henderson 2016). The common psychological side effects of stress are anxiety and depression. Direct relationships exist between loneliness and depression, suicidal thoughts (Killgore et al. 2020), and mental stress in all age groups (B. J. Smith and Lim 2020). Although home workspaces and distance working are not the focus of this paper, it is worth mentioning that loneliness as a risk factor for occupational stress deserves more attention from researchers and designers, during and after the COVID19 pandemic. Psychological distress can lead to behavioral distresses. Some examples of behavioral distresses are alcohol and drug abuse, tobacco abuse, aggression, violence, and accidents (Quick and Henderson 2016).

At the organizational level, the presence of personal distress could highly reduce the productivity of an organization as a result of personal dysfunction/low function. Studies conducted over the last decade have established that the work environment has a significant impact on North American employees since they spend at least $50 \%$ of their indoor time in the workplace (Fleury-Bahi, Pol, and Navarro 2017). Occupational stress-induced adverse effects on the organization manifest as absenteeism, labor turnover, disability, and productivity decline (Czabała, Charzyńska, and Mroziak 2011).

Most of an organization's operating costs are related to its staff. Thus, improving staff productivity by even as little as one percent can have a significant impact on the bottom line and a business's competitiveness (WGBC 2016). Many factors contribute to occupational stress, but research shows that the following are primary issues: lack of control, working night shifts, the disproportionate relationship between a worker's effort expended and the reward gained for that effort, unreasonably high demands, poor work environment, social isolation, inactivity, and violence at work (Leka and Jain 2010; Steptoe and Kivimäki 2013; P. Smith and Beaton 2008). Those factors are interconnected and interact with each other, although not all of them directly relate to the built environment.

In a study done by Quick and Henderson based on a systematic literature review, four broad categories of workplace demand that cause distresses are categorized as follows: 1) task demands (occupation, careers, workload, job insecurity); 2) role demands (role conflict and ambiguity); 3) physical demands (temperature, lighting, workplace design); and 4) interpersonal demands (social density, personality conflicts, leadership style, group pressures) (Quick and Henderson 2016). Of these categories, physical demands and interpersonal demands are those most directly related to the built environment. This classification is 
used in the present article when addressing the various areas of recommended interventions.

\section{The $\mathrm{t}$ baseline theory}

Due to the contemporary urban lifestyle, many people are constantly facing stress, much of which is caused by the physical environment. Most of the theories guiding the studies reviewed in the present paper are related in some non-trivial way to the theory of evolution. Specifically, stress is considered as one of the fundamental biological mechanisms and behavioral archetypes in the natural history of humans (Stevens 1982) as attested by scholars in fields as diverse as biology, psychology and anthropology, and subfields such as human behavioral ecology, evolutionary psychology and cultural evolution (Brown and Richerson 2014; Gillis and Gatersleben 2015).

Stress is the humans' natural reaction to threats. Fight-or-flight responses trigger several physiological mechanisms that work together to save human life when encountering a threat and temporarily suppress other mechanisms, such as the immune system (Segerstrom and Miller 2004). However, imminent existential threats are not the only events or circumstances which can trigger these physiological responses. Some environmental factors, work demands for example, can stimulate the same responses as physical threats in modern humans.

While the stress mechanism is designed to save species life when they encounter a life threat, the modern human lifestyle has created an environment in which humans are experiencing stress constantly (Segerstrom and Miller 2004) and chronic stress has become a major public health risk factor. Therefore, mitigating stress can be seen as a strategy in many fields, including architecture and planning, to improve the quality of life and public health (Brown and Richerson 2014; S. Kellert 2014; Grinde and Patil 2009). One of the possible approaches to mitigating this public health risk factor is to improve access to nature; studies have been conducted that demonstrate that access to nature and greenery plays a significant role in the reduction of stress (Sahlin et al. 2015; Hartig, Mang, and Evans 1991; Grinde and Patil 2009; S. Kellert 2014).

\section{Biophilia Hypothesis}

The fundamental need of humans for access to nature is a finding rooted in Human Behavior and Evolutionary Theory (Brown and Richerson 2014). The term biophilia was introduced by the social psychologist Erich Fromm; the word means love of life in Greek (W. Browning, Ryan, and Clancy 2014). It became part of the academic language in the 1980s through the work and writings of American biologist Edward O. Wilson, and was later expanded by Stephan Kellert (Browning, Ryan, and Clancy 2014; Brown and Richerson 2014; S. R. Kellert 1995). Biophilia is a relatively new hypothesis that is gaining increasing popularity in the building sciences; thus much of this paper is arranged around this pivot.

The Biophilia Hypothesis discusses the intrinsic inclination of humans to affiliate with nature that affects them neurologically and physiologically (Grinde and Patil 2009; S. R. Kellert 1995; W. Browning, Ryan, and Clancy 2014). The human body's autonomic nervous system plays an essential role in supporting this inclination. The system has two main parts: the sympathetic nervous system (the part that monitors the environment, registers potential threats and prepares the body for fight and flight responses) and the parasympathetic nervous system (the part that maintains the body's internal processes and facilitates calmness and a relaxed state) (W. Browning, Ryan, and Clancy 2014). The human desirable state is achieved through a balance of these two; however, our contemporary urban lifestyle puts people mostly in the sympathetic state (W. Browning, Ryan, and Clancy 2014). The biophilic objective is to enhance parasympathetic activity and reduce sympathetic activity (W. Browning, Ryan, and Clancy 2014).

Many successful modern architects and urban planners, e.g., Ebenezer Howard, Frank Lloyd Wright, and Le Corbusier (Fishman 2016) integrate nature with design. Many historical built environment design concepts [such as central courtyards (Alhorr et al. 2015; W. Browning, Ryan, and Clancy 2014), Persian gardens and garden cities (Norouzianpour, Rad, and Pishe 2012), and healing gardens that have been included as part of European hospitals and monasteries as far back as the Middle Ages (Velarde, Fry, and Tveit 2007)] are instinctively based on the relationship between nature and human satisfaction. Many of these approaches celebrate rather different aspects of nature from spiritual aspect to physical comfort; however, the biophilic framework focuses mostly on the health and well-being of users. Also, biophilic design endeavors to provide both scientific evidence for design and sets of guidelines based on reliable research. 
Biophilic design studies the relationship between human behavior, psychology, and well-being. The application of biophilic design is categorized by Kellert and Calabrese (2015) in three primary experiences: 1) direct experience of nature, 2) indirect experience of nature, and 3) experience of space and place (S. Kellert and Calabrese 2015). Table.1 is based on those three experiences and their 24 attributes (as set forth by Kellert and Calabrese) that are directly affiliated with the mitigation of stress and general well-being of people.

Biophilic design is stated as a design philosophy based on the Biophilia Hypothesis which encourages the use of natural systems and processes. To implement a biophilic design strategy, designers should consider the building occupants, location (context), and its function (Gillis and Gatersleben 2015). Kellert discussed that biophilic design is not about the temporary or insolate experience in one unit as it only would have a superficial and brief effect, but it is part of a comprehensive system that works with nature ( $\mathrm{S}$. Kellert 2015). He emphasized that disconnected strategies or individual approaches would not have a desirable outcome (S. Kellert 2015). In this approach, besides the physical demands, the psychological aspect of design (such as social interaction as a natural need of humans as a social species for having a healthy lifestyle) is addressed (S. Kellert 2015).

There is substantial evidence that biophilic design can enhance productivity, mitigate stress, improve well-being, promote collaborative workspaces, and increase satisfaction (Gray and Birrell 2014). A

Table 1: Experience and attributes of biophilic design

\begin{tabular}{|c|c|c|}
\hline \multicolumn{3}{|c|}{ Application of Biophilic Design } \\
\hline Direct Experience of Nature & Indirect Experience of Nature & Experience of Space and Place \\
\hline - $\quad$ Light & - Images of nature & - $\quad$ Prospect and refuge \\
\hline - Air & - Natural materials & - $\quad$ Organized complexity \\
\hline - Water & - Natural colors & - Integration of parts to wholes \\
\hline - Plants & - Simulating natural light \& air & - Transitional spaces \\
\hline - Animals & - Naturalistic shapes \& forms & - $\quad$ Mobility and wayfinding \\
\hline - Weather & - Evoking nature & - Cultural and ecological \\
\hline - $\quad$ Fire & - Age, change, \& the patina of time & attachment to place \\
\hline - $\quad$ Natural landscapes & - Information richness & \\
\hline and ecosystems & - Natural geometries & \\
\hline
\end{tabular}

Source: Kellert and Calabrese (2015) 
review of psychology literature, done by Cillis and Gatersleben, also finds significant positive effects of biophilic design attributes on recovery from mental fatigue and stress (Gillis and Gatersleben 2015). This study found that there is a good body of literature on the benefits of biophilia. However, they also believe that there are not enough studies on the importance and weight of each individual biophilic feature that Kellert classifies under experiences such as experiencing nature, direct and indirect experiences, and experiencing space and place (Gillis and Gatersleben 2015). In other words, the benefits of biophilic design for human health and well-being are recognized by researchers, but the importance of each individual biophilic element, its attributes, and the extent which each attribute contributes to the whole biophilic experience need to be studied more.

In another recent study by Yin and colleagues (2019), 30 participants were tested letting them experience, through the use of virtual reality (VR) technology, simulated open and enclosed office spaces designed with the biophilic principle (Yin et al. 2019). During this experiment, they first recorded blood pressure, heart rate, heart rate variability, and skin conductance level and, following that, administered cognitive tests to measure the participants' response time and creativity after experiencing three versions of the biophilic design (Yin et al. 2019). The results show that experiencing three spaces with biophilic elements reduced physiological stress indicators and increased creativity scores in participants (Yin et al. 2019).

Indeed, corporations can benefit financially from biophilic design since it would likely reduce healthcare costs and increase productivity. As an example, the Terrapin Bright Green report (2012) states that having views to nature from the workspace can lead to more than $\$ 2,000$ per worker per year savings (B. Browning et al. 2012). Moreover, this simple intervention can reduce 10 percent of employees (B. Browning 2015). Also, Browning (2015) stated that, based on the center for the Sacramento Municipal Utility District (SMUD) research, incorporation of biophilic intervention in an office building can save up to three times the cost of installing the intervention (B. Browning 2015). To sum, biophilia has numerous health benefits including improved indoor air quality, stress mitigation and increased occupant satisfaction; for that reason, when designing a facility, considering the biophilic aspects is crucial to creating a healthier, more productive work environment (Al Horr et al. 2016).

\section{DISCUSSION}

By reviewing the adverse effects of stress on the wellbeing and health of employees, it seems the first steps should be raising awareness (Kivimäki and Kawachi 2015), modifying the policies, and considering mitigation of other work-related demands that cause occupational stress since those would have a significant effect on the reduction of occupational stress in workplaces. Due to the importance of this issue in many countries, governments are trying to react to occupational stress through policy acts (Kivimäki and Kawachi 2015). For example, the European Agency for Safety and Health at Work has launched its Healthy Workplaces Campaign 2014-2015 to promote a positive, health-promoting, psychosocial work environment (Kivimäki and Kawachi 2015). On the international scale, the World Health Organization (WHO) is addressing occupational stress as a public health risk factor. The United States has a long history of addressing mental health at workspaces; the Occupational Safety and Health Act that dates back to 1970 (Pub. L. No. 91-596, 84 STAT. 1590, December 29, 1970 ) is one example. This act mandates the protection of human resources and is consistent with considering a range of factors influencing workers' wellbeing (Schulte et al. 2015).

Besides those general policies, in the realm of the built environment, the AIA Code of Ethics states that all architects should consider the well-being of people as their primary responsibility ("AIA Code of Ethics and Professional Conduct - AIA" 2017). In one of AIA's white papers, it is stated that nearly three-quarters of U.S. architects claim the health impacts of buildings are influencing their design decisions (Tinder and Schneidawind 2017). Besides all of the leading standards (ULI, LEED, and WELL), the high market demand among building owners for the inclusion of health-related factors is also shaping architectural design (Tinder and Schneidawind 2017). As described previously in this paper, chronic stress contributes to medical, psychological and behavioral distress that constitute a significant public health issue; thus architects must pay attention to the reduction of occupational stress in their design.

\section{Architectural interventions}

As a multidisciplinary field, public health not only includes social, economic, medical, and policymaking aspects, but also considers the built environment as an important aspect for health interventions. In fact, 


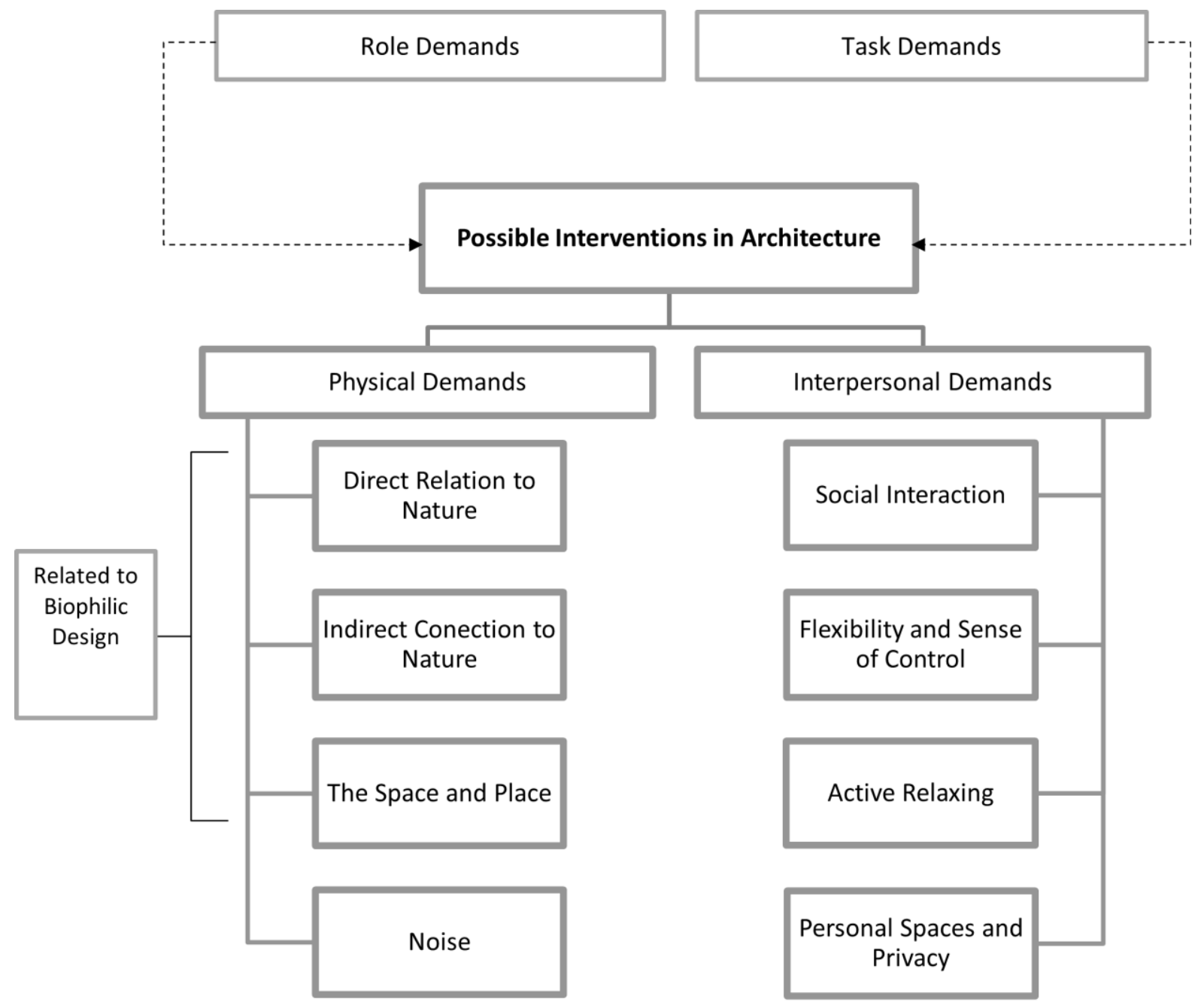

Diagram 1: Possible design interventions to mitigate occupational stress

public health directly deals with various aspects of community and community-based design which are related to architecture. In addition, architects, planners, designers, and other design-focused stakeholders in the creation of the urban built environment are now aware of their role in supporting people's health and well-being. Although intervention to mitigate occupational stress should be started at the urban planning and policymaking levels, this paper mostly addresses interventions related to architecture at the building scale.

Four categories of workplace demands (task, role, physical, and interpersonal demands) that cause distresses (Quick and Henderson 2016) are considered in this paper as a framework for categorizing design strategies for mitigating occupational stress in office buildings. Architects and designers have the greatest opportunity to positively influence worker well-being by focusing primarily (although not exclusively) on workers' physical demands and, to some extent, their interpersonal demands. Diagram 1 attempts to outline the process and relationships between distresses and design intervention strategies in the built environment.

All environment interventions related to an office building at the architectural level are classified into 
two major groups. The first group includes interventions that reduce stress by addressing physical needs. Providing access to nature is considered a key factor in this group of interventions. Access to nature could be passive or active and includes any activity that fosters engagement with nature, through any or all senses (Winterbottom and Wagenfeld 2015). Having access to nature can occur in the interior design, exterior landscape, and other visual forms in a building. In this categorization, another group of interventions is those which include Interpersonal needs. In the work environment, interpersonal demands are those that mitigate psychological challenges and mental stressors created by social activities or the lack thereof (issue of loneliness) in the office. This group of interventions also includes those that address the perception of safety and privacy on a personal level. While this paper does generalize somewhat with

Table 2: Design strategies that can be used as an evidence-based design toolkit

\begin{tabular}{|c|c|c|}
\hline $\begin{array}{c}\text { Categories Based } \\
\text { on the Main } \\
\text { Sources of Stress }\end{array}$ & $\begin{array}{c}\text { Intervention } \\
\text { Areas }\end{array}$ & Design Strategies for Mitigating Stress \\
\hline \multirow[t]{2}{*}{$\begin{array}{l}\text { Intervention } \\
\text { Related to the } \\
\text { Physical } \\
\text { Demands }\end{array}$} & $\begin{array}{l}\text { Direct Experience } \\
\text { of Nature }\end{array}$ & $\begin{array}{l}\text { 1. Flower boxes and potted plants in the office } \\
\text { 2. Interior landscape setting } \\
\text { 3. Water in the form of ponds and waterfalls } \\
\text { 4. Green walls } \\
\text { 5. Skylights } \\
\text { 6. Sufficient windows } \\
\text { 7. Workstations close to the windows to provide daylight } \\
\text { 8. Atriums } \\
\text { 9. Building orientation to maximize daylighting } \\
\text { 10. Daylight-imitating artificial light systems } \\
\text { 11. Roof gardens } \\
\text { 12. Balconies with plants, views to nature, or open space } \\
\text { 13. Thermal comfort } \\
\text { 14. Natural ventilation } \\
\text { 15. Aquarium, fish tanks, or fish in water ponds } \\
\text { 16. Pet-friendly environment } \\
\text { 17. Natural materials (organic) }\end{array}$ \\
\hline & $\begin{array}{l}\text { Indirect } \\
\text { Experience of } \\
\text { Nature }\end{array}$ & $\begin{array}{l}\text { 18. Views to outside without obstacles from each work- } \\
\text { station } \\
\text { 1. Curtain wall with shades for open offices } \\
\text { 2. Framing of outstanding natural elements in the dis- } \\
\text { tance such as mountains and forests (vista) } \\
\text { 3. Roof garden that makes a visual connection } \\
\text { 4. In cases with no view to natural elements or pleasant } \\
\text { views (e.g.,in dense urban areas): flower boxes at win- } \\
\text { dows to soften the views } \\
\text { 6. Pictures that represent aspects of nature } \\
\text { 7. Bird and water sounds } \\
\text { 8. Soundscaping }\end{array}$ \\
\hline
\end{tabular}


Table 2 (con't)

\begin{tabular}{|c|c|c|}
\hline $\begin{array}{l}\text { Categories Based } \\
\text { on the Main } \\
\text { Sources of Stress }\end{array}$ & $\begin{array}{l}\text { Intervention } \\
\text { Areas }\end{array}$ & Design Strategies for Mitigating Stress \\
\hline \multirow[t]{2}{*}{$\begin{array}{l}\text { Intervention } \\
\text { Related to the } \\
\text { Physical } \\
\text { Demands }\end{array}$} & $\begin{array}{l}\text { Space and Place } \\
\text { Experience }\end{array}$ & $\begin{array}{l}\text { 27. Organic plans and layouts (especially for open offices) } \\
\text { 28. Spacious but protected workstations (refuge) } \\
\text { 29. Diverse and unexpected spaces } \\
\text { 30. Task-based proportional design }\end{array}$ \\
\hline & Noise & $\begin{array}{l}\text { 31. Wall panels, ceiling baffles and other acoustic materials } \\
\text { for interior use (absorptive surfaces that decrease un- } \\
\text { wanted noise reverberation) } \\
\text { 32. Appropriate acoustic design of open offices } \\
\text { 33. Sound isolation from the exterior } \\
\text { 34. Separation of noisy activities in adjacencies } \\
\text { 35. Green buffer zone (landscape) } \\
\text { 36. Background sounds that cancel unwanted noise }\end{array}$ \\
\hline \multirow[t]{4}{*}{$\begin{array}{l}\text { Intervention Re- } \\
\text { lated to the Inter- } \\
\text { personal De- } \\
\text { mands }\end{array}$} & $\begin{array}{l}\text { Flexibility and } \\
\text { Control }\end{array}$ & $\begin{array}{l}\text { 37. Controls on sound options } \\
\text { 38. Controls on daylight options } \\
\text { 39. Temperature controls } \\
\text { 40. Flexibility of posture and location (workstation flexibil- } \\
\text { ity) } \\
\text { 41. Individually controllable lighting systems (artificial light) }\end{array}$ \\
\hline & $\begin{array}{l}\text { Social } \\
\text { Interaction }\end{array}$ & $\begin{array}{l}\text { 42. Gathering spaces inside } \\
\text { 43. Gathering spaces outside } \\
\text { 44. Furniture setting that promotes dialogue } \\
\text { 45. Flexible configurations via movable furniture }\end{array}$ \\
\hline & Privacy & $\begin{array}{l}\text { 46. Visual privacy of workstations } \\
\text { 47. A personal bubble around individuals as a design factor } \\
\text { (flexible workstations) }\end{array}$ \\
\hline & $\begin{array}{l}\text { Active } \\
\text { Relaxing }\end{array}$ & $\begin{array}{l}\text { 48. Meditation spaces (preferably in a natural setting) } \\
\text { 49. Entertainment spaces } \\
\text { 50. Circulation that includes green elements }\end{array}$ \\
\hline
\end{tabular}

respect to workforce needs and behaviors, it is important for designers to keep in mind and seek to provide flexible environments that can meet the needs and preferences of different individuals as well as assess the environment on a case by case basis.

The adverse effects of occupational stress are significant on both the health of individual employees and an organization's productivity. Based on literature from design and aligned fields, this paper proposes a list of potential design interventions for stress mitigations to be included in an evidence-based design toolkit for offices and workplaces (Table 2). The fifty strategies in Table 2 pull considerations around stress and design from the literature and synthesize them in 
terms of potential design strategies and stress interventions.

Some post-occupancy studies examined some of the aforementioned strategies (Gensler Research Institute 2020; Frontczak et al. 2012); for example, in a two-year collaborative project between the University of Western Sydney (UWS) and one of Australia's largest construction companies, Brookfield Multiplex (BM), a temporary construction site office was redesigned with biophilic design strategies (Gray and Birrell 2014). Office features identified as "bespoke open plan site shed space; natural lighting and ventilation; introduction of plants; and collaborative workspaces" had been implemented to create a new, hopefully, healthier environment and allow for the recording of data addressing the impact on employee health and well-being (Gray and Birrell 2014). The post-occupancy study of this redesigned workspace found some perceived benefits such as: "enhanced collaboration amongst staff, including across teams, improved morale, and mitigation against stress (Gray and Birrell 2014)." However, some of the strategies mentioned in Table 2 resulted from the synergy of other design strategies or their combination, rather than being directly concluded from experimental research. In the following section, each intervention area is explained in more detail.

\section{INTERVENTIONS RELATED TO WORKERS PHYSICAL DEMANDS}

Interventions related to physical demands have four subcategories. Three of those subcategories are related to biophilic needs; the fourth addresses noise. For this section, Kellert's biophilic design strategy labels are used to avoid confusion: 1 ) direct relation to nature, 2) indirect relation to nature, and 3) space and place.

\section{Direct relation to nature}

While the connection with nature and greenery can happen both inside and outside of the building, employees practically spend most of their time inside the building and workspace (Marcus and Sachs 2014). Thus, indoor natural elements would likely have more impactful mental health benefits for the occupants than those found outside. Interior design interventions that integrate nature or mimic natural systems with stress mitigation, increased creativity, and enhanced illness recovery, which can have financial benefits such as a reduction in the use of sick days (Tranel 2020).

\section{Indoor greenery}

Employees can connect to indoor nature by seeing, touching and smelling indoor vegetation, and by hearing nature sounds either through an open window or recordings of nature such as birds and water, or even by viewing nature images both still and moving (Marcus and Sachs 2014). Even simple changes such as introducing potted plants in an office building are reported as an intervention that can affect the mood states, stress levels, and well-being of a building's occupants (Dannenberg, Frumkin, and Jackson 2011; Gray and Birrell 2014; Grinde and Patil 2009). The indoor plants and views of nature in an office can improve attention capacity and prevent fatigue in work tasks with high attention requirements (Raanaas et al. 2011). It is worth mentioning that in another study, the potted indoor plants were found to be less effective than outdoor landscape. In general, outdoor landscapes have a more substantial positive impact on the general well-being of occupants (Grinde and Patil 2009) and cannot be replaced by indoor ones. However, indoor greenery is still beneficial when outdoor greenery is not feasible.

More rewarding approaches such as green walls are becoming more common as an interior element in office buildings. There are various types of green walls available based on different structures such as freestanding walls, tray systems, and panel/modular systems (Architizer 2017). The big advantage of these green wall systems is that they can introduce a large surface of greenery inside, and potentially outside, without occupying much usable square footage in the office where floor space is at a premium.

\section{Lightning}

There is a direct connection between sunlight penetration and job satisfaction (Leather et al. 1998). Light affects people in nonvisual ways through both the skin and eyes; lack of light can cause medical distress (Veitch and Galasiu 2012). For instance, insufficient exposure to daytime sunlight, as well as exposure to nocturnal light pollution over time, are related to an increased risk of some cancers (Welker 2016).

It is critical that "workspaces provide regular access to natural light, feature lighting systems that consider circadian rhythms, and reduce sources of glare and visual discomfort" (Welker 2016) due to the direct 
link between physical comfort and stress. Architects can use light modeling, simulations, and other technologies to ensure adequate designed levels of equivalent melanotic lux at workstations throughout the day, thereby impacting the quality of rest at night (Welker 2016).

Besides providing natural illumination, windows have additional restorative effects by providing views to the outdoors which help mitigate stressful experiences (Hartig, Mang, and Evans 1991; Ulrich 1984; Veitch, Christoffersen, and Galasiu 2013), as discussed in the Biophilia Hypothesis section earlier in this paper. Also, there is a direct correlation between worker satisfaction and distance to a window in a private office. In other words, having access to a window will improve work performance and productivity (Frontczak et al. 2012). However, designers should consider possible thermal comfort and glare problems when the workstation is close to the windows (Aries 2010). Also, studies show that the adjacency of workstations to windows can lead to reduced absenteeism in organizations (B. Browning 2015).

Having lamps with lighting quality similar to daylight can have comparable effects on humans. The light color and warmth should be close to natural sunlight and an equivalent melanotic lux (Veitch, Christoffersen, and Galasiu 2013; Welker 2016) to have positive effects on occupant mental health. This strategy also can reduce Seasonal affective disorder (SAD), an annual recurrent syndrome associates with seasonal depression (Nussbaumer et al. 2015). For instance, new LED technologies can provide a real alternative to conventional lighting, with luminaire efficiencies that are now more than traditional technologies (WGBC 2016). In contrast with efficient fluorescent bulbs that have a blue light reported to be "depressing", new LEDs can mimic the spectrum of natural sunlight, have higher color-rendering abilities, and can mitigate stress and anxiety (Michael Heller 2016).

In another study addressing the daylight features of the Biophilia Hypothesis, Oregon Hall (which houses the administrative and student service offices of The University of Oregon in Eugene, Oregon) was the locus for a study designed to explore whether differences exist in the relationship between workplace view and sick days taken by three categories of occupants: those with a view of nature, those with a view of urban structures, and those without any view (Elzeyadi 2011). The study also identifies daylight availability and better light quality as a contributor to the reduction of absent days. Study findings demonstrate that poor ratings of both light quality and views are correlated with significantly more absentee days (Elzeyadi 2011).

\section{The physical connection to nature outdoors}

As discussed before, human interaction with nature has a direct relationship to relaxation and well-being (Gillis and Gatersleben 2015; Winterbottom and Wagenfeld 2015). Also, outdoor open spaces provide a context for employees to socialize and engage in both active relaxation, entertainment, and recreation.

\section{Comfort}

The WELL Building Standard confirms that physical comfort can impact mental stress (IWBI 2020). AIA's white paper by Welker claimed that "variables such as humidity, airspeed, metabolic rate, and clothing affect comfort, productivity, and stress levels" (Welker 2016). Thermal flexibility is important in providing occupants both comfort and a sense of control. In open offices, this flexibility may be difficult to achieve, but strategies such as having thermal gradient areas to meet employees' different individual comfort zones, or flexible workspaces where employees can move around to find out their comfort zone, can give occupants the freedom to choose the desirable workstation, in the most comfortable thermal zone, and improve their satisfaction (Welker 2016).

\section{Indirect relation to nature}

Windows and skylights can make the boundary of space seem permeable and extend the visual boundaries of interior spaces to the outside (Veitch, Christoffersen, and Galasiu 2013). Having a window in a refuge area makes an interior space more mentally satisfactory, providing a higher level of the prospect as explained by the concept called 'Prospect and Refuge' in psychology (Veitch, Christoffersen, and Galasiu 2013). The prospect-refuge theory, as an environmental pattern, describes the desirable balance between settings where occupants have the opportunity to sit without disturbance (refuge) and having a vista with the ability to observe their surroundings (prospect) and their role in provoking the sense of mystery, comfort, and safety (Dosen and Ostwald 2013). Similarly, the view of nature from an employee's workstation can help alleviate stress and improve well-being through physiological calming 
(Marcus and Sachs 2014; Veitch, Christoffersen, and Galasiu 2013). Velarde and colleagues introduce the three ways that visual connection to nature can improve occupant mental health: short-term recovery from stress or mental fatigue, earlier physical recovery from illness, and long-term general enhancement of health and well-being (Velarde, Fry, and Tveit 2007, 199). Research by Velarde and colleagues shows that the view to a green landscape has the best therapeutic effects on people compared to the effects of having a view to either open water (sea, ocean, rivers, etc.) or to hardscape (urbanscape) (Grinde and Patil 2009; Veitch, Christoffersen, and Galasiu 2013). However, differentiating among landscape design styles and comparing the impacts of each style on mental health requires more research (Aries 2010; Veitch, Christoffersen, and Galasiu 2013). What is clear is that having views of nature and green landscape from the building provides better restorative effects (Velarde, Fry, and Tveit 2007) compared to other forms of landscape. In cases where a view to natural elements from workstations is not available - or the view is not pleasant (such as a dense urban area) - pictures of nature or other art forms can be substituted as an alternative restorative method (Veitch, Christoffersen, and Galasiu 2013).

\section{Sounds of nature}

The restorative effects of nature are not limited to the visual aspect of it. Hearing the pleasant sounds of nature - the rippling of a stream or the sound of birds chirping - can be soothing and enhance relaxation. Natural sounds, as background sounds, can mask the unwanted noises in the built environment. Well Standard version one, in the "Mind" category, recommended the use of an audio device with nature sounds for a "designated quiet space for focus, contemplation, and relaxation (IWBI 2020, 142)."

Water features in a building not only improve the air quality and aesthetics of a space, such features also can generate pleasing background noise. Water sound has restorative effects and can reduce stress, according to biophilia theory (Yin et al. 2019). The sound can be generated by waterfalls, water fountains, and running water, in and outside of the building. As an optional feature, WELL AP v1, Feature 100, recommended including at least one water feature for every $100,000 \mathrm{ft}^{2}$ in projects greater than 100,000 $\mathrm{ft}^{2}$ to achieve the emotional and psychological benefits of nature (IWBI 2020). However, considering WELL standards that address sanitizing the water and controlling contamination is recommended (IWBI 2020).

Soundscape designs include various types of sounds and auditory natural stimuli (Ratcliffe, Gatersleben, and Sowden 2013), such as bird sounds. Studies show that listening to bird sounds has positive effects on both attention restoration and recovery from stress (Ratcliffe, Gatersleben, and Sowden 2013). Birds can be introduced into the environment by using interior landscape and atriums as their habitat. However, not all types of bird sounds have similar restorative effects (Ratcliffe, Gatersleben, and Sowden 2016). Research done by Ratcliffe and colleagues shows that bird sounds related to green spaces, spring and summer seasons, hours of daylight, and time of activity have higher perceived restorative potential. On the other hand, bird sounds correlated with exotic and marine ecosystems, and nonavian animals, have lower perceived restorative potential (Ratcliffe, Gatersleben, and Sowden 2016).

\section{Space and place}

Prospect-refuge theory suggests that human survival and evolution required humans to develop a preference for places that afforded a good vantage point from which to spot existential threats and, at the same time, provided protective cover and thus a higher degree of safety from predators (Stamps 2014). Applying this concept to the general layout and feel of designed interior spaces serves much the same purpose today - to satisfy one of the evolutionary psychological needs of people to reduce stress by having a high level of refuge and prospect (S. Kellert 2014). An environment that provides restorative, healing effects will offer both high levels of prospect, such as an open view and clear vision, as well as high levels of refuge for seclusion. In contrast, an environment without sufficient refuge and prospect features can increase stress and attention fatigue (Gatersleben and Andrews 2013). Thus, it is important to consider those frameworks in design floor plans, forms and interior spaces.

WELL Standard V1 states that the experience of natural elements and nature-derived patterns can enhance the experience, mood and happiness of building occupants; on the other hand, interior spaces that are considered to be cold, sterile and lifeless can lessen positive experience, mood and happiness (IWBI 2020, 146 and 156). Also, based on biophilia theory, the design patterns and layouts that 
represent nature, such as organic floor plans, could have restorative outcomes. Designers should deliberately integrate nature's patterns by using natural patterns and processes and considering human evolution theory (International Living Future Institute 2014).

To possibly mitigate stress and improve a sense of comfort, incorporating components that deliver visual complexity, balance and proportion can be considered as a design intervention for an office building (IWBI 2020, 154 and 155). The proportion of space is a contributor to mental stress, as explained by prospect-refuge theory. In addition to that, the type of task that is going to be done in a space is another factor to consider when deciding on a proportion that will create a relaxing and comfortable space. Users whose tasks require a higher level of concentration often prefer smaller spaces, and those who are dealing with creative and collaborative tasks often prefer larger or open-plan design (Vischer 2007). To sum, the quality of spaces and the way they are perceived by the users, despite comfort factors, correlate with mental stress. The main factors that define the quality of the space and can also mitigate stress are correct proportion, visually pleasing aesthetics, and naturederived patterns in design.

\section{Noise}

Noise is any unwanted audible sound (Barientos et al. 2004). Noise has several adverse effects on human mental health; thus it is important to reduce unwanted indoor and outdoor noise to boost social interaction, learning, satisfaction, and productivity (IWBI 2020). In research done by Burns et al. (2016), it was found that added noise within the workplace significantly increases heart rate (Burns et al. 2016). An increased heart rate is a notable adverse health outcome as it is associated with the release of stress hormones in a human's body (Burns et al. 2016). The adverse effects of noise can be found at all ages, including in children (Evans, Bullinger, and Hygge 1998), verifying the severity of this risk factor.

Most office tasks benefit from a degree of noise control to enable employees to perform their jobs efficiently, making the building's acoustic design a crucial part of the overall office design (Al Horr et al. 2016). WELL Standards recommends four main interventions to improve sound comfort inside a building: 1) controlling reverberation time, 2) sound masking (for spaces that are extremely quiet and even small sounds can become disturbing), 3) employing sound- reducing surfaces (on ceilings and vertical surfaces), and 4) sound barriers (between spaces that generate noise (IWBI 2020). Also, it is important to consider noise as a factor for zoning the office; the task that generates a considerable amount of unwanted sound should be separated or contained by design elements.

\section{INTERVENTIONS RELATED TO INTERPERSONAL DE- MANDS}

As mentioned before, the stress mitigating interventions in this paper are classified into two groups based on the user's interpersonal (social) and physical needs. In this section, the environmental interventions that relate to employee's social interaction and mental health are going to be discussed. The important concepts here are: 1 ) flexibility and sense of control, 2) social interaction, 3) active relaxing, and 4) personal space and privacy.

\section{Flexibility and sense of control}

Employees have different social determinants of health $(\mathrm{ADOH})$ and personalities; therefore, a diverse set of design strategies should be employed in an office setting to be able to confront the adverse effects of occupational stress efficiently (Stickle and Scott 2016). Lack of control over an environment, in any form, will result in tension and stress (Aronsson 1989), such as the inability to control light quality (Veitch et al. 2010). Thus, flexibility in the workspace allows employees to identify and locate themselves in their thermal comfort zone, which would help reduce their overall stress levels (Welker 2016). A growing office planning style called activity-based work (ABW) environments is growing in popularity and suggests providing employees with a choice of office setting based on the type of work task (Hoendervanger et al. 2016). However, it seems that the effects of this strategy may be overestimated; many employees - due to personal preferences and/or type of tasks - typically do not like to switch work locations frequently during the day. (Hoendervanger et al. 2016). A flexible office space approach should consider having a variety of 'quiet' and 'loud' zones, which could support both private and collaborative spaces for workers to utilize (Welker 2016).

\section{Social Interaction}

Social isolation is another reliable predictor of perceived stress and can impact the productivity of both the employee and the institute (Ward Thompson et 
al. 2016). Social interaction can be encouraged among employees and other people with local green spaces outside (Ward Thompson et al. 2016). In early 2020, the COVID-19 pandemic forced a massive number of people to be quarantined around the globe. Many employees have been working from home, in social isolation, for months. This situation can trigger many mental health and psychosocial problems, even in people who were mentally healthy and had good levels of well-being before the pandemic (Usher, Huller, and Jackson 2020).

As the paradigm of working continues to shift from office culture to distance working, extremely higher rates of self-isolation and loneliness are occurring. Even after the pandemic, many employees might not return to their previous positions which means the loneliness could be a long-term public health risk factor and a mental stress agent that need to be addressed. Despite all the advantages that distance working might have for an employee, a recent study done by Gensler confirms that people still prefer the office when they have the choice (Gensler Research Institute 2020). The novel coronavirus pandemic in 2020 demonstrates that in the long run - even with all of the communication interfaces and technological advancements - it could be difficult for organizations to address social isolation (loneliness) as a health risk factor.

In Gensler's recent white paper (2020), Stromquist argues that employees' behavior and social interaction patterns might change during the offices re-occupation period, after the pandemic, since employees might be cautious about interacting with their peers in their usual way pre-pandemic. Post-pandemic approaches to office design that more rigorously consider virus transmission to be limited to strategies such as widening corridors, more private offices, distanced workstations, and automatic doors and faucets, risk losing social networks in the office that are known as neighborhoods or intimacy cycles. Gensler suggests that open-office plans should comprise neighborhoods (intimacy cycles) of approximately thirty people; this mid-sized grouping is between the larger scale of a close network (approximately fifty people) and the smaller scale of a sympathy group (approximately fifteen people) that are now commonly seen in office spaces (Stromquist 2020; Ro 2020). In summary, designers and management teams should emphasize maintaining a sense of community among coworkers and foster social interaction.

\section{Personal spaces and privacy}

The work setting and design of workspaces can negatively impact the stress level of an employee due to feeling a lack of control of personal space. In other words, how we comprehend, manage and cope with stress is associated with this sense of control (Winterbottom and Wagenfeld 2015). Many employees in office spaces report that privacy is essential to workplace satisfaction (Danielsson and Bodin 2009). Also, individuals need differing levels of spaces between themselves, forming a personal bubble (Winkelhake 1975) between themselves and others to feel comfortable. Thus, having a flexible workstation layout, or workstation options, can provide one level of desirable personal space.

The 2020 Gensler U.S. Workplace Survey shed light on an additional important social factor regarding the growing trend of open environments and unassigned seating; workers shared a need for private spaces that can be personalized (Gensler Research Institute 2020). Having a private workspace and a sense of ownership of that space, while considering other comfort factors such as cleanliness, noise, ergonomics, and technology, can help to mitigate rising stress levels in office environments (Gensler Research Institute 2020).

\section{Active relaxing}

As discussed, occupational stress can cause significant mental health problems for employees in officebased professions. One intervention to manage stress and recover from mental fatigue is physical activity (Calogiuri et al. 2016). In alignment with biophilia theory, Calogiuri et al. (2015) support implementing 'green exercise interventions' with their findings that the restorative effects of exercising in nature are higher than exercising indoors. Thus, having a place available for exercise nearby in an outdoor green space could be one design intervention to support stress restoration.

\section{CONCLUSION}

Sufficient evidence exists to support the theory that access to nature and greenery plays a significant role in the reduction of stress. The author utilizes a crossdisciplinary literature review to classify the theories that address the occupational stress that occurs in work environments. The limitation in this review was that occupational stress is mostly combined with another factor in the general well-being of the user and 
these together affect many aspects of the productivity, satisfaction and mental health of workers. In public health literature, most research focuses on diseases caused by stress and associated medical stressors. Also, public health researchers mostly focused on other risk factors, such as night shifts and aging, but rarely addressed the impacts of the designed environment. More research at the intersection of public health and design is needed to explore how the built environment causes and/or can mitigate occupational stress in workplaces.

In the architecture literature, at present, there are not enough first-hand experimental studies related to occupational stress to address causality or correlation. When it comes to behavioral studies in architecture, the focus is mostly on more general concerns such as safety, mental health and habitability, and comfort. Existing studies of occupational stress in relation to the built environment are less practical for design practice since these studies lack clarity in their methods and use undefined technical terms, such as disease vectors and agents, borrowed from other fields.

The literature on occupational stress in the disciplines of management, business and psychology is more reliable and better established than the literature on this topic in other fields. These studies have goals that are concerned primarily with improving the measurable productivity and quality of work life. However, environmental factors related to occupational stress are not their main concerns. In general, this review illustrates that there is not enough research directly considering the physical environment as a contributor to chronic occupational stress in office environments, in any of the mentioned fields of study, as this topic is intertwined with many other areas of interest, making it hard to study in insolation.

Both the Prospect and Refuge theory and Biophilia hypotheses are directly related to architecture and other built environment professions. On a practical level, architecture firms and public health organizations are trying to bridge the gap between built environment and health by working together more closely to improve people's quality of life. Today there are several practical standards in the design profession such as the WELL Building Standard (IWBI 2020) and Biophilic Design (Browning, Ryan, and Clancy 2014) that contain practical guidelines for addressing many public health concerns. However, even in those guidelines, aspects related to mental health are not sufficiently addressed, particularly when compared to the extent of what they offer relative to physical safety and disease prevention.

The literature review shows strong evidence that access to nature in various forms has beneficial healing and social interaction effects crucial for human mental health. Also, flexible design that provides control over the physical aspect of the environment is a key factor to mitigate occupational stress. Social aspects of design and human interaction address another group of important interventions for improving employee's wellbeing. Designers should select the best interventions that fit the scope of their project; however, they should keep in mind that none of the recommended areas of interventions, introduced in Table 2 are sufficient by themselves in creating an environment that supports the mental health of employees.

\section{Suggestions for future studies}

Future studies should include experimental research in the field of occupational stress and its relationship to the built environment that considers the building scale, the urban scale and the scales in between. Future research should be classified based on different tasks of focus for employees, as well as different social determinants of health for different employee populations. Another important study would be a comparison study of different-sized companies, their office arrangements, and operational stress factors. Classifying the design strategies based on the different causal factors would help to complete the toolkit and improve its efficacy.

Also, there is concern about the recent post-COVID19 office design guidelines (Tranel 2020), since social isolation is a common issue that is mostly missed in these approaches. It is important to reassess the mentioned strategies based on employee tasks and social determinants. Loneliness is an important issue that is mostly unaddressed by the post-Covid-19 approaches. Loneliness, as a public health risk factor during the COVID-19 pandemic, is very tangible and highly visible, but there are not assurances that things will go back to 'normal' after the pandemic is over. To arrive at best practice systems, post-pandemic studies are needed to investigate the health issues (beyond just infectious disease control) found in the built environment to reach a balance between mental health and physical health. 
As discussed, the intervention areas are classified into two categories around physical and interpersonal needs. Based on the literature, some important physical factors were found to be absent from the conversation such as the color of interior spaces and the impact of different landscape settings in different climates. In the interpersonal category, more experimental research is warranted on the effectiveness of different activities or facilities in the office that are commonly used to boost employee mood. Also, the role of adjacent public spaces and the quality of them in mitigating occupational stress can be an important topic in future research in this field. Even though there is considerable literature on workers' well-being and satisfaction in general, still a lot needs to be done to complete this puzzle, especially when it comes to mental stress.

\section{Acknowledgements}

Special thanks to Michaele Pride, Assoc. AIA, NOMA, Professor of Architecture and Mark C. Childs, AIA, Professor Emeritus of the School of Architecture and Planning, the University of New Mexico, for their generous continuing support and to Dr. David Weiss, Associate Professor of the College of Arts \& Sciences, the University of New Mexico, for his reviews and comments. Also, I would like to thank Dr. Traci Rose Rider, Assoc. AIA, LEED AP, WELL AP, Assistant Professor, School of Architecture, North Carolina State University for her guidance throughout the editing process and to the anonymous reviewers of the article for their generous and helpful suggestions.

\section{References}

Adli, Mazda. 2011. "Urban Stress and Mental Health." Retrieved September 16: 2014.

"AIA Code of Ethics and Professional Conduct - AIA." 2017. Accessed July 26.

https://www.aia.org/pages/3296-code-of-ethicsand-professional-conduct.

Al Horr, Yousef, Mohammed Arif, Amit Kaushik, Ahmed Mazroei, Martha Katafygiotou, and Esam Elsarrag. 2016. "Occupant Productivity and Office Indoor Environment Quality: A Review of the Literature." Building and Environment 105 (August): 369-89. doi:10.1016/j.buildenv.2016.06.001.
Alhorr, Yousef, Mohammed Arif, Tabassum Bano, Charles Egbu, Ahmed Mazroei, and Esam Elsarrag. 2015. "Creating a Better Healing Environment in Qatari Healthcare Sector: Exploring the Research Agenda for the Future." International Journal of Sustainable Built Environment 4 (1): 158-64. doi:10.1016/j.ijsbe.2015.03.007.

Architizer. 2017. "How to Specify: Green Walls." Architizer. November 6. https://archi-

tizer.com/blog/how-to-specify-green-walls/.

Aries, Myriam. 2010. "Windows, View, and Office Characteristics Predict Physical and Psychological Discomfort." Journal of Environmental .... https://www.academia.edu/418228/Windows_View_and_Office_Characteristics_Predict_Physical_and_Psychological_Discomfort.

Aronsson, Gunnar. 1989. "Dimensions of Control as Related to Work Organization, Stress, and Health." International Journal of Health Services 19 (3): 45968. doi:10.2190/N6KQ-HWA0-H7CJ-KUPQ.

Barientos, M. C., D. I. Nelson, T. Driscoll, N. K. Steenland, L. Punnett, and M. A. Fingerhut. 2004. "Chapter 21. Selected Occupational Risk Factors." World Health Organization. Comparative Quantification of Health Risks. Global and Regional Burden of Disease. Attributable to Selected Major Risk Factors. Ezzati M, Lopez AD, Rodgers A, Murray CJL 1: 1651-52.

Brown, Gillian R., and Peter J. Richerson. 2014. “Applying Evolutionary Theory to Human Behaviour: Past Differences and Current Debates." Journal of Bioeconomics 16 (2): 105-28. doi:10.1007/s10818013-9166-4.

Browning, Bill. 2015. "Healthier Workplaces, Happier Employees." People and Strategy 38 (3). Human Resource Planning Society: 14.

Browning, Bill, Chris Garvin, Catie Ryan, Namita Kallianpurkar, Leslie Labruto, Siobhan Watson, and Travis Knop. 2012. "The Economics of Biophilia." Terrapin Bright Green LLC. http://clients.edmullen.com/terrapin/.

Browning, William, Catherine Ryan, and Joseph Clancy Clancy. 2014. "14 Patterns of Biophilic Design." Terrapin Bright Green. http://www.terrapinbrightgreen.com/reports/14-patterns-of-biophilic-design/. 
Burns, Katrina N., Kan Sun, Julius N. Fobil, and Richard L. Neitzel. 2016. "Heart Rate, Stress, and Occupational Noise Exposure among Electronic Waste Recycling Workers." International Journal of Environmental Research and Public Health 13 (1). doi:10.3390/ijerph13010140.

Calogiuri, Giovanna, Katinka Evensen, Andi Weydahl, Kim Andersson, Grete Patil, Camilla Ihlebæk, and Ruth K. Raanaas. 2016. "Green Exercise as a Workplace Intervention to Reduce Job Stress. Results from a Pilot Study." Work 53 (1): 99-111. doi:10.3233/WOR-152219.

Czabała, Czesław, Katarzyna Charzyńska, and Barbara Mroziak. 2011. "Psychosocial Interventions in Workplace Mental Health Promotion: An Overview." Health Promotion International 26 (suppl_1): i70.

Dannenberg, Andrew L., Howard Frumkin, and Richard Jackson, eds. 2011. Making Healthy Places: Designing and Building for Health, Well-Being, and Sustainability. Washington, D.C: Island Press.

Dosen, Annemarie, and Michael Ostwald. 2013. "Prospect and Refuge Theory: Constructing a Critical Definition for Architecture and Design." International Journal of Design in Society 6 (January): 9-23. doi:10.18848/2325-1328/CGP/v06i01/38559.

Elzeyadi, Ihab. 2011. "Daylighting-Bias and Biophilia: Quantifying the Impact of Daylighting on Occupants Health." US Green Building Council. Http://Www. Usgbc.

Evans, Gary W., Monika Bullinger, and Staffan Hygge. 1998. "Chronic Noise Exposure and Physiological Response: A Prospective Study of Children Living Under Environmental Stress." Psychological Science 9 (1): 75-77. doi:10.1111/1467-9280.00014.

Figueroa-Fankhanel, Frances. 2014. "Measurement of Stress." Psychiatric Clinics of North America, Stress in Health and Disease, 37 (4): 455-87.

doi:10.1016/j.psc.2014.08.001.

Fishman, R. 2016. "Urban Utopias in the Twentieth Century: Ebenezer Howard, Frank Lloyd Wright, and Le Corbusier." In , 23-50.

doi:10.1002/9781119084679.ch1.

Fleury-Bahi, Ghozlane, Enric Pol, and Oscar Navarro, eds. 2017. Handbook of Environmental Psychology and Quality of Life Research. International
Handbooks of Quality-of-Life. Cham: Springer International Publishing. doi:10.1007/978-3-319-31416-7.

Frontczak, M., S. Schiavon, J. Goins, E. Arens, H. Zhang, and P. Wargocki. 2012. "Quantitative Relationships between Occupant Satisfaction and Satisfaction Aspects of Indoor Environmental Quality and Building Design." Indoor Air 22 (2): 119-31. doi:10.1111/j.1600-0668.2011.00745.x.

Gatersleben, Birgitta, and Matthew Andrews. 2013. "When Walking in Nature Is Not Restorative-The Role of Prospect and Refuge." Health \& Place 20 (Supplement C): 91-101. doi:10.1016/j.healthplace.2013.01.001.

Gensler Research Institute. 2020. “U.S. Workplace Survey 2020 | Research \& Insight." A PUBLICATION OF THE GENSLER RESEARCH INSTITUTE. https://www.gensler.com/research-insight/workplace-surveys/us/2020.

Gillis, Kaitlyn, and Birgitta Gatersleben. 2015. "A Review of Psychological Literature on the Health and Well-being Benefits of Biophilic Design." Buildings 5 (3): 948-63. doi:10.3390/buildings5030948.

Gray, Tonia, and Carol Birrell. 2014. "Are BiophilicDesigned Site Office Buildings Linked to Health Benefits and High Performing Occupants?" International Journal of Environmental Research and Public Health 11 (12): 12204-22. doi:10.3390/ijerph111212204.

Grinde, Bjørn, and Grete Grindal Patil. 2009. “Biophilia: Does Visual Contact with Nature Impact on Health and Well-Being?" International Journal of Environmental Research and Public Health 6 (9): 233243. doi:10.3390/ijerph6092332.

Gruebner, Oliver, Michael A. Rapp, Mazda Adli, UIrike Kluge, Sandro Galea, and Andreas Heinz. 2017. "Cities and Mental Health." Deutsches Ärzteblatt International 114 (8): 121-27. doi:10.3238/arztebl.2017.0121.

Hartig, Terry, Marlis Mang, and Gary W. Evans. 1991. "Restorative Effects of Natural Environment Experiences." Environment and Behavior 23 (1): 3-26. doi:10.1177/0013916591231001.

Hoendervanger, Jan Gerard, Iris De Been, Nico W. Van Yperen, Mark P. Mobach, and Casper J. Albers. 2016. "Flexibility in Use: Switching Behaviour and Satisfaction in Activity-Based Work Environments." Journal of Corporate Real Estate 18 (1). Emerald 
Group Publishing Limited: 48-62. doi:10.1108/JCRE10-2015-0033.

International Living Future Institute. 2014. "Living Building Challenge Sm 3.0.-A Visionary Path to a Regenerative Future." International Living Future Institute Seattle, WA.

IWBI. 2020. "The Well Building Standard V1 with Q3 2020 Addenda." International WELL Building Institute pbc.

Kellert, Stephen. 2014. "Biophilia and Biomimicry: Evolutionary Adaptation of Human versus Nonhuman Nature." Intelligent Buildings International, 1-6. doi:10.1080/17508975.2014.902802.

Kellert, Stephen, and Elizabeth Calabrese. 2015. "The Practice of Biophilic Design." Retrieved from Biophilic Design. Com.

Kellert, Stephen R. 1995. The Biophilia Hypothesis. Island Press.

Killgore, William D. S., Sara A. Cloonan, Emily C. Taylor, and Natalie S. Dailey. 2020. "Loneliness: A Signature Mental Health Concern in the Era of COVID-19." Psychiatry Research 290 (August): 113117.

doi:10.1016/j.psychres.2020.113117.

Kivimäki, Mika, and Ichiro Kawachi. 2015. "Work Stress as a Risk Factor for Cardiovascular Disease." Current Cardiology Reports 17 (9): 74. doi:10.1007/s11886-015-0630-8.

Leather, Phil, Mike Pyrgas, Di Beale, and Claire Lawrence. 1998. "Windows in the Workplace: Sunlight, View, and Occupational Stress." Environment and Behavior 30 (6): 739-62. doi:10.1177/001391659803000601.

Leka, Stavroula, and Aditya Jain. 2010. "WHO | Health Impact of The Psychosocial Hazards of Work: An Overview." WHO. http://www.who.int/occupational_health/publications/hazardpsychosocial/en/.

Marcus, Clare Cooper, and Naomi A. Sachs. 2014. Therapeutic Landscapes: An Evidence-Based Approach to Designing Healing Gardens and Restorative Outsdoor Spaces. Hoboken, New Jersey: Wiley.

Michael Heller. 2016. "Innovations in Lighting Technology Impact More than Efficiency."

https://www.aia.org/articles/20866-innovations-inlighting-technology-impact-mo.
National Research Council (US) Committee on Recognition and Alleviation of Distress in Laboratory Animals. 2008. Recognition and Alleviation of Distress in Laboratory Animals. Washington, DC: The National Academies Press. doi:10.17226/11931.

Norouzianpour, Hirbod, Mehri Motahari Rad, and Samane Motaghi Pishe. 2012. "PERSIAN GARDENS ARE SUSTAINABLE GARDENS: SCRUTINIZE THE SUSTAINABILITY FEATURES IN PERSIAN GARDENS."

http://www.mukogawa-

u.ac.jp/ iasu2012/pdf/iaSU2012_Proceed-

ings_507.pdf.

Nussbaumer, Barbara, Angela Kaminski-Hartenthaler, Catherine A. Forneris, Laura C. Morgan, Jeffrey H. Sonis, Bradley N. Gaynes, Amy Greenblatt, et al. 2015. "Light Therapy for Preventing Seasonal Affective Disorder." Cochrane Database of Systematic Reviews, no. 11. John Wiley \& Sons, Ltd. doi:10.1002/14651858.CD011269.pub2.

Palmer, Stephen, and Windy Dryden. 1994. "Stress Management: Approaches and Interventions." British Journal of Guidance \& Counselling 22 (1): 5-12. doi:10.1080/03069889408253661.

Quick, James Campbell, and Demetria F. Henderson. 2016. "Occupational Stress: Preventing Suffering, Enhancing Well-being." International Journal of Environmental Research and Public Health 13 (5): 459. doi:10.3390/ijerph13050459.

Raanaas, Ruth, Katinka Evensen, Debra Rich, Gunn Sjøstrøm, and Grete Patil. 2011. "Benefits of Indoor Plants on Attention Capacity in an Office Setting." Journal of Environmental Psychology 31 (March): 99105. doi:10.1016/j.jenvp.2010.11.005.

Ratcliffe, Eleanor, Birgitta Gatersleben, and Paul T. Sowden. 2013. "Bird Sounds and Their Contributions to Perceived Attention Restoration and Stress Recovery." Journal of Environmental Psychology 36 (Supplement C): 221-28.

doi:10.1016/j.jenvp.2013.08.004.

- - - 2016. "Associations with Bird Sounds: How Do They Relate to Perceived Restorative Potential?" Journal of Environmental Psychology 47 (Supplement C): 136-44. doi:10.1016/j.jenvp.2016.05.009.

Reinten, Jikke, P Ella Braat-Eggen, Maarten Hornikx, Helianthe Kort, and Armin Kohlrausch. 2017. "The Indoor Sound Environment and Human Task Performance: A Literature Review on the Role of Room 
Acoustics." Building and Environment 123 (July). doi:10.1016/j.buildenv.2017.07.005.

Rider, Traci Rose, Margaret van Bakergem, Jinoh Park, Xi Wang, and J. Aaron Hipp. 2018. "Design, Development, and Public Health." Enquiry The ARCC Journal for Architectural Research 15 (1): 62-74. doi:10.17831/enq:arcc.v15i1.571.

Ro, Christine. 2020. "Dunbar's Number: Why We Can Only Maintain 150 Relationships." Accessed July 22. https://www.bbc.com/future/article/20191001-dunbars-number-why-we-can-only-maintain-150-relationships.

Sahlin, Eva, Gunnar Ahlborg, Artur Tenenbaum, and Patrik Grahn. 2015. "Using Nature-Based Rehabilitation to Restart a Stalled Process of Rehabilitation in Individuals with Stress-Related Mental IIIness." International Journal of Environmental Research and Public Health 12 (2): 1928-51.

doi:10.3390/ijerph120201928.

Schulte, Paul A., Rebecca J. Guerin, Anita L. Schill, Anasua Bhattacharya, Thomas R. Cunningham, Sudha P. Pandalai, Donald Eggerth, and Carol M. Stephenson. 2015. "Considerations for Incorporating 'Well-Being' in Public Policy for Workers and Workplaces." American Journal of Public Health 105 (8): e31-44. doi:10.2105/AJPH.2015.302616.

Segerstrom, Suzanne C., and Gregory E. Miller. 2004. "Psychological Stress and the Human Immune System: A Meta-Analytic Study of 30 Years of Inquiry." Psychological Bulletin 130 (4): 601-30. doi:10.1037/0033-2909.130.4.601.

Smith, Ben J., and Michelle H. Lim. 2020. "How the COVID-19 Pandemic Is Focusing Attention on Loneliness and Social Isolation." Public Health Research \& Practice 30 (2): e3022008.

Smith, P., and D. Beaton. 2008. "Measuring Change in Psychosocial Working Conditions: Methodological Issues to Consider When Data Are Collected at Baseline and One Follow-up Time Point." Occupational and Environmental Medicine 65 (4): 288-95; quiz 295-96. doi:10.1136/oem.2006.032144.

Stamps, Arthur. 2014. Literature Review of Prospect and Refuge Theory: The First 214 References. doi:10.13140/2.1.4642.6249.

Steptoe, Andrew, and Mika Kivimäki. 2013. "Stress and Cardiovascular Disease: An Update on Current
Knowledge." Annual Review of Public Health 34 (1): 337-54. doi:10.1146/annurev-publhealth-031912114452.

Stevens, Anthony. 1982. "Archetype: A Natural History of the Self," January.

Stickle, Fred E., and Kelly Scott. 2016. "Leadership and Occupational Stress." Education 137 (1): 27-38.

Stromquist, Brian. 2020. "Taking Care of Each Other in the Post-Pandemic Open Office | Dialogue Blog | Research \& Insight." Gensler. Accessed July 22. https://www.gensler.com/research-insight/blog/community-in-the-post-pandemic-openoffice.

Tinder, Matt, and John Schneidawind. 2017. "Nationwide Survey Finds Healthy Buildings Becoming a Key Design Priority for Both Architects and Building Owners - AIA." Accessed July 26.

https://www.aia.org/press-releases/17161-nationwide-survey-finds-healthy-buildings-be:31.

Tranel, Ben. 2020. "How Should Office Buildings Change in a Post-Pandemic World? | Dialogue Blog | Research \& Insight." Gensler. Accessed July 22. https://www.gensler.com/research-insight/blog/how-should-office-buildings-change-in-apost-pandemic-world.

Ulrich, R. S. 1984. "View through a Window May Influence Recovery from Surgery." Science (New York, N.Y.) 224 (4647): 420-21.

Usher, Kim, Navjot Bhullar, and Debra Jackson. 2020. "Life in the Pandemic: Social Isolation and Mental Health." Journal of Clinical Nursing n/a (n/a). doi:10.1111/jocn.15290.

Veitch, Jennifer, Jens Christoffersen, and Anca Galasiu. 2013. "WHAT WE KNOW ABOUT WINDOWS AND WELL-BEING, AND WHAT WE NEED TO KNOW." In .

Veitch, Jennifer, and Anca Galasiu. 2012. The Physiological and Psychological Effects of Windows, Daylight, and View at Home: Review and Research Agenda. doi:10.4224/20375039.

Veitch, Jennifer, C L. Donnelly, Anca Galasiu, G R. Newsham, D M. Sander, and C D. Arsenault. 2010. "Office Occupants? Evaluations of an IndividuallyControllable Lighting System," January. doi: $10.4224 / 20374060$. 
Velarde, M. D., G. Fry, and M. Tveit. 2007. “Health Effects of Viewing Landscapes - Landscape Types in Environmental Psychology." Urban Forestry \& Urban Greening 6 (4): 199-212. doi:10.1016/j.ufug.2007.07.001.

Vischer, Jacqueline. 2007. The Effects of the Physical Environment on Job Performance: Towards a Theoretical Model of Workspace Stress. Vol. 23. doi:10.1002/smi.1134.

Ward Thompson, Catharine, Peter Aspinall, Jenny Roe, Lynette Robertson, and David Miller. 2016. "Mitigating Stress and Supporting Health in Deprived Urban Communities: The Importance of Green Space and the Social Environment." International Journal of Environmental Research and Public Health 13 (4): 440. doi:10.3390/ijerph13040440.

Welker, Matt. 2016. "Six Design Decisions That Will Entice Clients and Improve Health." https://www.aia.org/articles/19541-six-design-decisions-that-will-entice-client:31.

WGBC. 2016. "Building the Business Case: Health, Well-being, and Productivity in Green Offices | World Green Building Council." http://www.worldgbc.org/news-media/building-business-case-healthwell-being-and-productivity-green-offices.

Winkelhake, CA. 1975. "Personal Space and Interpersonal Space." Man-Environment Systems 5 (6): 35152.

Winterbottom, Daniel M., and Amy Wagenfeld. 2015. Therapeutic Gardens: Design for Healing Spaces. First edition. Portland, Oregon: Timber Press.

Yin, Jie, Nastaran Arfaei, Piers MacNaughton, Paul J. Catalano, Joseph G. Allen, and John D. Spengler.

2019. "Effects of Biophilic Interventions in Office on Stress Reaction and Cognitive Function: A Randomized Crossover Study in Virtual Reality." Indoor Air 29 (6): 1028-39. doi:10.1111/ina.12593. 